\title{
El reto de la especialización en fisioterapia en España
}

\author{
Lorenzo A. JUSTO-COUSIÑO
}

La adaptación de la diplomatura en fisioterapia al Espacio Europeo de Educación Superior surgió para dar respuesta a una necesidad tanto profesional como social en España. Actualmente destaca el tema de las especialidades en fisioterapia, abordado en el último Congreso Nacional de Fisioterapia que organizó la Asociación Española de Fisioterapeutas (AEF) [1], en donde se ratificó la idoneidad del máster oficial como el modelo más adecuado para la especialización. Previamente, la AEF había establecido esta vía formativa para las especialidades [2].

La AEF establece las siguientes características básicas que debe presentar la formación de especialización: misma denominación de los títulos, formación específica y con los mismos contenidos entre programas, formación clínica garantizada con los mismos programas formativos y carga horaria, homogeneidad en los sistemas de evaluación, acreditación de los centros clínicos asociados, reconocimiento oficial de las competencias profesionales adquiridas y acreditación de los programas por medio de la Agencia Nacional de Evaluación de la Calidad y Acreditación (ANECA) [2].

Sin embargo, es necesario reflexionar sobre las posibles dificultades que podrían acaecer con los nuevos másteres de especialización. Para ello se analizó la asignatura de fisioterapia del deporte en los grados en fisioterapia, ya que es una de las ramas de especialización que tiene mayor presencia en la formación de posgrado [3].

Mediante una búsqueda web se analizaron los planes de estudio de fisioterapia existentes en el curso 2016-2017 (64 titulaciones de grado, según el Ministerio de Educación, Cultura y Deporte) para evaluar la asignatura de fisioterapia del deporte bajo sus diversas denominaciones. Los datos más destacables de las guías docentes consultadas $(n=52)$ fueron los siguientes: la asignatura era de carácter obligatorio en el $25 \%$ de los grados, optativo en el $59,4 \%$, y en el $15,6 \%$ no se encontraba disponible la guía docente o los contenidos se incluían en otras asignaturas. Los contenidos más presentes de esta asignatura fueron: lesiones deportivas $(78,8 \%)$, generalidades de la fisioterapia deportiva $(65,4 \%)$ y tratamiento general de lesiones deportivas $(57,7 \%)$. Estos resultados concuerdan con estudios previos donde se analizó esta misma asignatura en las diplomaturas [4].

La variabilidad observada ha motivado la presente reflexión sobre las especialidades porque se puede constatar que, para una misma rama de conocimiento, la denominación difiere, el carácter de la asignatura es variable y los contenidos no son homogéneos. Considerando esta heterogeneidad en un modelo formativo que lleva cerca de una década de vida, se requiere una elevada meticulosidad para poder generar formación de especialización que sea equiparable en todo el territorio nacional y para formar fisioterapeutas con el mismo nivel de especialización, aunque debe tenerse en cuenta que la presente observación se trata de una mera extrapolación del Grado en Fisioterapia a las especialidades.

Por otra parte, es necesario considerar las limitaciones en la oferta académica actual de los másteres oficiales, principalmente la temática y el número de plazas. El Ministerio de Educación, Cultura y Deporte [5] indexa únicamente 36 entradas para nivel de estudios 'máster' y la palabra clave 'fisioterapia'. Se puede constatar que el $25 \%$ de los másteres están enfocados a la fisioterapia del deporte y de la actividad física, siendo ésta la temática más abordada. De todos los másteres donde hay información disponible (14 de 36), el número medio de plazas ofertadas es de 33,9 $\pm 13,8$.

No podría finalizarse esta reflexión sin destacar el gran avance que supondrá la especialización reconocida en fisioterapia para la consolidación de la profesión. Igualmente, resulta meritoria la intachable trayectoria de la AEF, lo que avala que el diseño e implantación de las especialidades se realizará con el máximo rigor.
Grupo de Investigación i+HeALTH. Departamento de Ciencias de la Salud. Universidad Europea Miguel de Cervantes. Valladolid, España.

Correspondencia:

Dr. Lorenzo Antonio Justo Cousiño. Universidad Europea Miguel de Cervantes. Padre Julio Chevalier, 2. E-47012 Valladolid.

E-mail:

ljusto@uemc.es

(C) 2019 FEM 
Bibliografía

1. Ramos-Gómez F, Suárez-Serrano C, González-Iglesias J, Marcén-Román Y, Pampín-Lado P, Pallín-Tato E, et al. Conclusiones del XV Congreso Nacional de Fisioterapia y I Congreso Nacional de Fisioterapia del Deporte. Prescripción de ejercicio y especialidades en fisioterapia. Fisioterapia 2018 40: $167-8$.

2. Fernández R, Souto S, González L, Lista A, Gómez A. Asociación Española de Fisioterapeutas. Proyecto de Especialidades en Fisioterapia. Madrid: Asociación Española de Fisioterapeutas; 2015.
3. Serra-Llobet P. Análisis de las enseñanzas de posgrado para fisioterapeutas, tras la adaptación universitaria al Espacio Europeo de Educación Superior [tesis doctoral]. Barcelona: Universitat Internacional de Catalunya; 2015.

4. Aguiló-Pons A, Moreno-Gómez C, Martínez-Bueso P, PazLourido B. Relevancia de la formación sobre ejercicio físico y deporte en los planes de estudio de fisioterapia. Fisioterapia 2006; 28: 291-7.

5. Qué estudiar y dónde en la universidad (QEDU): búsqueda de títulos. Madrid: Ministerio de Educación, Cultura y Deporte; 2019. URL: https://www.educacion.gob.es/notasdecorte/ busquedaSimple.action. [03.01.2019]. 